\title{
Effects of Shareholder Groups on the Factoring Institutions Profitability: Evidence from Germany
}

\author{
Sven $\operatorname{Koch}^{1}$ \\ ${ }^{1}$ Institute for Business Administration and International Finance, Helmut Schmidt University, University of the \\ Federal Armed Forces Hamburg, Hamburg, Germany \\ Correspondence: Sven Koch, Ph. D. Student, Institute for Business Administration and International Finance, \\ Helmut Schmidt University, University of the Federal Armed Forces Hamburg, Hamburg, Germany. E-mail: \\ koch@hsu-hh.de
}

Received: August 24, 2015

Accepted: September 5, 2015

Online Published: October 25, 2015

doi:10.5539/ijef.v7n11p39

URL: http://dx.doi.org/10.5539/ijef.v7n11p39

\begin{abstract}
The significant role of trade credit in financing large companies and small and medium-sized enterprises leads to high stocks of account receivables within the balance sheets of German firms. As a result the importance of working capital financing is growing and the demand for accounts receivables financing (factoring) increases. The German factoring industry is dominated by banks. In addition to bank-owned financial institutions, many non-bank financial institutions are represented on the market. In a context of a continuing market consolidation, it is of interest whether there are differences in terms of profitability depending on shareholder groups (financial institution, non-financial institution, non holding). The German factoring market is an extremely growing market with further growth potential in an ongoing market consolidation. A further market consolidation is probable because the administrative expenses of small financial institutions and institutions without any holding are high. However, subsidiaries of a financial holding or non-financial holding show significantly lower administrative expenses. The results show that the profitability of the financial institutions is significantly influenced by the shareholders and the size of the institution. Financial institutions of a financial holding (bank-owned) are significantly less profitable than institutions without any holding or institutions of a non-financial holding. A similar picture emerges in the achieved margins of factors.
\end{abstract}

Keywords: account receivable finance, factoring, financial instruments, non-bank financial institutions, profitability, shareholder

\section{Introduction}

The significant role of trade credit in financing of large companies and small and medium-sized enterprises (SMEs) leads to high stocks of account receivables within the balance sheets of European firms. In the United Kingdom more than $80 \%$ of daily business transactions are made through on trade credit terms (Summers \& Wilson, 2000). In Germany accounts receivables of SMEs are representing over all main sectors up to $10.3 \%$ of total assets. In the main sector of wholesale and retail trade this adds up to $19.3 \%$. The high accounts receivables in balance sheets of SMEs show the importance of trade credits for SMEs of various economic sectors (Bank for the Accounts of Companies Harmonized, 2015; Bundesbank, 2012).

The importance of trade-sided debt financing is shown in many studies. Study results show that the profitability of SMEs is positively affected by use of trade credit. In addition trade credits can be a useful tool to support sales and business growth (Martínez-Sola, García-Teruel, \& Martínez-Solano, 2014; Summers \& Wilson, 2003). Another study shows that a decreasing number of days of outstanding accounts receivables have a positive impact on the SME's profitability (Deloof, 2003).

Also the importance of working capital financing is growing, so that the demand for accounts receivables financing (factoring) increases. From the perspective of the supplier, factoring enables granting trade credit and an immediate inflow of liquidity and at the same time from the perspective of the customer an individual term of payment. Therefore factoring is an important source of working capital financing and tends to become a primary source of short term external financing in selected industries (e.g. wholesale and manufacturing). This indicates that the global factoring industry is a growing industry, especially at good economic growth (Klapper, 2006). 
It is assumed that factoring is larger in countries with greater economic development and growth (Klapper, 2006). Accordingly, the most pronounced factoring markets exist in the largest European economies. As measured by "gross domestic product" (GDP), the largest European economies are Germany, the United Kingdom (UK), France and Italy. In 2013, this is confirmed in Europe, the largest economies achieved the largest factoring turnover: Germany (171.3 €bn), the United Kingdom (308.1 €bn), France (200.5 €bn) and Italy (178.0 €bn) (Factor Chain International).

The factoring turnover in Germany is high. But a comparison of national factoring ratios shows that the German factoring market has further potential for development. Thereby the factoring ratio is measured by the ratio of volume of purchased receivables to GDP. The German factoring ratio amounts to $6.1 \%$. This implies that $6.1 \%$ of the GDP is financed by factoring which is relatively low compared to the UK (15.3\%), Italy (11.1\%) and France (9.5\%). (European Central Bank, 2015; Factor Chain International, 2015).

Table 1 shows the average factoring turnover growth of the largest European industry countries in the period between 2007 and 2013.

Table 1. Factoring turnover growth in European industry countries

\begin{tabular}{|c|c|c|c|c|c|c|c|c|c|c|c|c|}
\hline \multirow[t]{2}{*}{ Year } & \multicolumn{3}{|c|}{ Germany } & \multicolumn{3}{|c|}{ UK } & \multicolumn{3}{|c|}{ France } & \multicolumn{3}{|c|}{ Italy } \\
\hline & $€ b n$ & $\begin{array}{c}2000 \\
=100\end{array}$ & $\begin{array}{c}\% \\
\text { growth }\end{array}$ & $€ b n$ & $\begin{array}{r}2000 \\
=100\end{array}$ & $\begin{array}{c}\% \\
\text { growth }\end{array}$ & $€ b n$ & $\begin{array}{r}2000 \\
=100\end{array}$ & $\begin{array}{c}\% \\
\text { growth }\end{array}$ & $€ b n$ & $\begin{array}{r}2000 \\
=100\end{array}$ & $\begin{array}{c}\% \\
\text { growth }\end{array}$ \\
\hline 2007 & 89.0 & 100 & & 286.4 & 100 & & 121.7 & 100 & & 122.8 & 100 & \\
\hline 2008 & 106.0 & 119.10 & 19.10 & 188.0 & 65.62 & -34.37 & 135.0 & 111.00 & 0.11 & 128.2 & 104.40 & 0.04 \\
\hline 2009 & 96.0 & 107.87 & -9.43 & 195.6 & 68.28 & 58.56 & 128.2 & 105.36 & -0.05 & 124.3 & 101.18 & -0.03 \\
\hline 2010 & 130.0 & 146.07 & 35.41 & 226.2 & 78.97 & 11.15 & 153.3 & 125.97 & 0.20 & 143.7 & 117.06 & 0.16 \\
\hline 2011 & 158.0 & 177.53 & 21.53 & 268.0 & 93.57 & 2.44 & 174.6 & 143.50 & 0.14 & 175.2 & 142.66 & 0.22 \\
\hline 2012 & 157.0 & 176.40 & -0.63 & 291.2 & 101.64 & -8.32 & 186.5 & 153.29 & 0.07 & 181.9 & 148.11 & 0.02 \\
\hline 2013 & 171.2 & 192.46 & 9.10 & 308.0 & 107.54 & -2.59 & 200.5 & 164.77 & 0.07 & 178.0 & 144.95 & -0.02 \\
\hline 2014 & 189.8 & 223.37 & 16.06 & & & & & & & & & \\
\hline \multicolumn{3}{|c|}{ Average growth over the period } & 13.02 & & & 4.47 & & & 0.09 & & & 0.07 \\
\hline
\end{tabular}

Notes. factoring turnover in billions of Euro; Sources: Lea and Trollope (1996), German Factory Association (2015) and Factor Chain International.

The results, as well as the low factoring ratio, indicate that the German factoring market is an extremely growing market $(13 \%)$ with further growth potential. The total factoring turnover growth in the German factoring industry seems unstoppable and is partly due to a strong increase in factoring clients. The industry has experienced an average increase of $16.9 \%$ and an overall increase in the amount of 113.8\% from 2009 (8 840 clients) to 2014 (18 900 clients). The major factors are organized in the German Factoring Association (25 factors) and the German Federal Factoring Association for Medium-Sized Businesses (25 factors) and focused primarily on large firms as well as SMEs. In 2014 the German total factoring turnover was around $190 € \mathrm{bn}$. The factors of the German Factoring Association are representing approximately $90 \%$ of the total German factoring market (German Factoring Association, 2015).

At the same time a significant market consolidation takes place. Since supervision of factoring institutions (factors) in 2008, the total number of factors decreased from 275 (2009) to 199 (2014). This was due to the after-effects of the financial crisis and to the expenses associated with the new regulatory regime (BaFin, 2011, 2014).

The highest developed factoring market can be found in the UK. The total factoring turnover amounts to $308 € b n$ and nearly $72 \%$ of the turnover are represented by the „Big Four“ banks. This shows that the larger players are bank-owned which leads to the conclusion that factors are an extension of the banking industry in the UK (Hawkins, 1993; Lea \& Trollope, 1996; see Table 1). In Germany factoring is considered as non-bank financing instrument and is often chosen by firms due to the independence of (house-) banks (German Factoring Association, 2011). How does it look like in Germany, which is known to be a bank-based economy?

However, empirical studies on the global factoring market, as well as the US und the UK market, are available. Studies on the German factoring market are rare and the factors themselves not available. One reason might be, that the general information on the German factoring industry are available. But compared to the UK market, the institute-related information about German factors are limited. Against the background of a growing market in 
Germany, it might be interesting from the perspective of factors, as well as SMEs, who dominates the market, which income will be generated. As well it would be worth to know which expenses, especially administrative expenses, are incurred.

The present study supplements the existing research on factoring by an analysis of the financial statements of the German factors and answers the question if the shareholders and the size of the factors have an effect on the profitability of factors. Furthermore, the development of the German factoring market is illustrated by the development of the factors. The article is organized as follows. The following section reviews the relevant literature. Section 4 develops hypotheses on factors profitability. Afterwards section 5 describes the data sample and the methodology. Section 6 gives a brief overview of the main results. Section 7 discusses the empirical results and the final section summarizes and concludes this article.

\section{Literature Review}

Klapper (2006) analyses the provision of factoring services in 48 countries around the world from 1993 to 2003. The empirical results show that factoring is larger in countries with greater economic development and growth. Furthermore, the results highlight the importance of good credit information for the success of factoring. Klapper (2006) argues that in a growing economy, the number of customers as well as the stock of receivables increase in a way that more firms use factoring for working capital financing. In addition, credit information positively influence the provision of factoring, because of the lower information asymmetry and the fact that risks of the sellers are transferred to the factor. A study from Borgia, Swaleheen, Jones and Weeks (2010) is also based on panel data set of 59 countries around the world and over a period between 1995 and 2005. The analysis examines the influence of the quality of governance to the level of factoring activity measured by the countries' factoring turnover. In addition to Klapper (2006), these results indicate that in countries with weak governance the level of factoring will increase when there is an improvement in governance and in the incidence of corruption the factoring turnover decreases. Both studies show this level of economic activity, the level of credit and financial information as well as the level of governance and corruption are key determinants of factoring activities in global factoring.

The analysis from Smith and Schnucker (1993) is based on results of a survey of 770 US firms in 1991. Smith and Schnucker (1993) regard the factoring decision as a choice about organizational structure on the basis of transaction costs theory of organization. They follow Coase (1937) and assume the effect of information and monitoring costs (transaction costs) as well as the effect of transaction-specific investments on the choice of organizational structure (vertical integration). In this case, the choice means a decision between integrated management of trade credit or specialized factoring contracts. The aim here is to reduce or avoid arising transaction costs. Their analysis shows that transaction costs are important determinants for the choice between integrating credit management and factoring as well as factoring is more likely to be used when information and monitoring costs are high. Furthermore, they point out that factoring is more likely and beneficial for sellers with geographically dislocated buyers and few repeat sales to any given buyer as well as for buyers with incomplete information about the seller (Smith \& Schnucker, 1993).

Summers and Wilson (2000) considered the factoring market in the UK in 1994 and examined the preferences of factors and the function of the demand for short-term financing as determinants for the use of factoring. They point out that factoring is higher demanded by small companies which are credit rationed and/or under financial pressure. The availability of factoring for small firms is more likely if the risks for the factor decrease. This is possible by a close day to day relationship between the factor and the firm. Thereby the existing information asymmetry can get over because the factor receives valuable information about the transaction partners and the business (Summers \& Wilson, 2000).

The study from Hartmann-Wendels and Stöter (2012) is based on a survey conducted in Germany from 2010 and examines the firm's decision to manage account receivables. They distinguish between the choice of internal or external management of trade credits (full-service factoring or in-house factoring). Hartmann-Wendels and Stöter (2012) show that companies use factoring to short-term financing or to diversify their financing mix (independence from banks). In addition factoring is used by firms to cover potential payment defaults while increasing equity ratios. They also confirm the findings of Smith and Schnucker (1993) that factoring is chosen to reduce the transaction costs. The results show that factoring is more likely if the firm has many different and dislocated customers. Further it is shown that the firm size has an influence on the choice of factoring types. Small and growing firms tend to full-service factoring whereas larger companies rather tend to in-house factoring (Hartmann-Wendels \& Stöter, 2012). 


\section{Hypothesis}

\subsection{The Profitability of Factors Is Negatively Influenced by Age and Size (Hypothesis 1)}

According to Smith and Schnucker (1993), the reputation of the factor is a critical element of the efficient functioning of factoring markets, especially in markets with incomplete information. An excellent reputation of the factor is assumed given a long presence in the factoring market or a recognized own brand name or brand name of the holding company (i.g. commercial banks, or factoring subsidiaries of bank holding companies). Furthermore, it can be assumed that large factors have a better opportunity to gain industry and credit information. This allows large factors a better business outlook and adjusting the factoring conditions. Thus, the factor is a financial and information intermediary within the triangular relationship between factor, sellers and buyers. Due to this key role, the factor has high quality monitoring information (Diamond, 1984; Smith \& Schnucker, 1993). It is likely that level and quality of information as well as the reputation of the factors increase with size and age.

According to Smith and Schnucker (1993) and Hartmann-Wendels and Stöter (2012), large firms are more likely to use internal management of trade credits or in-house factoring. So, presumably, these factors use the price mechanism to open up new markets. With declining financing costs, the probability of factoring increases which results from business with large firms with inevitably lower margins for the factor. Furthermore, it can be assumed that factoring is more likely if the factor reduced financing (factoring) costs. Further, large factors often have higher financial resources to finance large volumes. Consequently, large factors have a lower level of profitability and a smaller margin.

\subsection{The Profitability of Factors Is Influenced by Shareholders (Hypothesis 2)}

The hypothesis of the shareholder is closely linked to the hypothesis of the age and size effects. The descriptive statistics of the sample shows that factors without any holding are significantly different from subsidiary factors of non-financial and financial holding (see Table 2 and Table A1). Factors without any holding are significantly smaller. It is assumed that subsidiary factors have better financing conditions (amount and conditions), due to the holding company as well as the existing exclusive banking relationships. Thus, it can be assumed that with the size of the factor the size of the customer increases. Hence, the profitability and margin decline. Another explanation for low margins of subsidiaries is that holdings skim off incomes of the factor through increased financing terms (i.g. high interest expenses). Anyway, the proof cannot be checked due to the available data. In addition, it can be assumed that the reputation of the holding company has a significant impact on the business of the subsidiary as well as existing customer relationships of the holding (i.g. customer information, distribution channels and cross-selling business).

\section{Data and Methodology}

\subsection{Data}

The sample consists of 66 factors in the period between 2010 and 2013. Up to march $16^{\text {th }} 2015$, the Federal Financial Supervisory Authority (BaFin) lists 197 financial service institutions that engage in factoring. Excluded are institutions which are specialized exclusively to medical practitioners and pharmacies (settlement entities), institutions which hold an authorization to financial leasing, institutions with other legal forms than AG, $\mathrm{GmbH}$ and $\mathrm{GmbH} \& \mathrm{Co}$. KG as well as institutions which are exempt from the publication of the annual financial statements (Note 1). Since some factors did not give full particulars in the balance sheets and income statements, an unbalanced sample is used. The necessary data for the calculations was extracted from the annual financial statements and management reports as well as the Hoppenstedt database. Factoring turnover, interest rates and gross domestic product are gathered from German Factoring Association, European Central Bank and Federal Statistical Office. The data was gathered in march 2015.

\subsection{Variables}

The regressions of the following analysis include three dependent variables in order to make a statement to factors profitability. In the first regression profitability is measured by the ratio of interest and commissions income to receivables from another customer $(P R O F)$. Factoring is defined as an ongoing purchase of receivables on the basis of standard agreements, with or without recourse (German Banking Act). Hence, it is assumed that the balance sheet position receivables from the customer is equal to the average factoring volume of the factors. Because of sheet date values seasonal and time effects are excluded likewise the average days in receivables. The amount of the receivables from customer corresponds to the purchased receivables. No distinction is made between the different types of factoring (i.g. domestic and international factoring as well as full-service factoring and in-house factoring). In the second regression, margin is used to measure performance 
$(M A R)$. The margin of the factors measured by the ratio of interest and commission income minus interest and commission expenses to interest and commission income. The interest and commission income are the factoring costs which represent the SMEs factoring interest and the factoring fee. In the third regression, the profitability is measured by the ratio of earnings before taxes to total assets $(R O A)$.

All regression analysis include predictor variables found by previous literature to explain firm and non-bank financial institution profitability and to test these hypotheses (Martínez-Sola, García-Teruel and Martínez-Solano, 2014; Sakyi, Ofoeda, Kyereboah-Coleman and Abor, 2014). Firm-specific and industry-related factors are used as predictor variables. The predictor variable shareholder is represented by three dummy variables. First, non-holding factors are independent factors without any holding companies (dummy_nh). Second, non-financial holding companies are shareholders which are no banks or financial services institutions as defined in the German Banking Act. But there is the possibility of further subsidiaries which are credit or financial services institutions (dummy_nfh). And third, financial holding companies are shareholders which are credit or financial services institutions as defined in the German Banking Act (dummy_fh). The variable dummy_nh represents the control group in the following analysis. All dummy variables are taking the value of 1 if it is a non-holding, non-financial holding or financial holding company, otherwise 0 .

Further predictor variables are size (SIZE) and age $(A G E)$. These are measured by total assets and by the total number of years the factors are existing. A further variable is the GDP growth rate $(G D P)$. In various studies GDP growth is chosen as a control variable, because the level of economic activity affects the factoring turnover (Klapper, 2006). Interest expenses are also an integral part of this analysis, because interest rates might affect the refinancing costs of factors and thus the profitability. Therefore the interest level measured by the growth of three month Euro Interbank Offered Rate (INT) measured by the European Central Bank.

Against the background of ongoing consolidation the costs are in focus. In addition to the refinancing costs are administrative expenses crucial, in particular in relation to the average volume of receivables. Therefore the variable administrative expenses $(A D M E X P)$ is used and measured by the ratio of administrative expenses to receivables from the customer. For descriptive evaluation of the factoring industry also the receivables $(R E C)$ is of interest. This is measured by total receivables from customers. The receivables take no further influence on the following analysis, since they are highly dependent on the SIZE.

\subsection{Descriptive Statistics}

The sample consists of factors with average of total assets between $12846 € b n$ and $577284 € \mathrm{bn}$. Receivables from customer represent on average $74.7 \%$ of total assets. Here, the average volume of receivables of the five largest factors (PB Factoring GmbH, Eurofactor AG, CommerzFactoring GmbH, SüdFactoring GmbH and Coface Finanz $\mathrm{GmbH}$ ) was $78.9 \%$ (2013). The top five factors are bank-owned. Furthermore 26 factoring institutions are without any holding (39\%), 21 with non-financial holding (32\%) and 19 with financial holding (29\%). Table 2 and Table A1 present descriptive statistics for the variables covering 66 factoring institutions from 2010 to 2013.

The factoring industry generated interest and commissions income of $2049 € b n$ with a cumulative average receivables from customer of $49040 € \mathrm{bn}$. The average profitability (PROF) and margin (MAR) amounted to $22 \%$ and $75 \%$. The data shows that subsidiaries of a financial holding have a lower average profitability (9\%), while factors without any holding (27\%) as well as subsidiaries of a non-financial holding (29\%) end up with have a much higher profitability. The period from 2010 to 2013 meant a decline in profitability for all factors. When comparing the margins $(M A R)$, a similar picture emerges. Subsidiaries of a financial holding have an average margin of $67 \%$. This contrasts with average margins of up to $80 \%$ in subsidiaries of a non-financial holding. A downward trend cannot be determined at the margins. The average margins of all factors have risen from $65 \%$ (2010) to $71 \%$ (2013). The mean ROA of all factors is surprisingly low at $4 \%$. Furthermore, there is no trend from 2010 to 2013.

The $A G E$ of the factors is on average more than 10 years. With an average of 14.8 years, subsidiaries of financial holdings are the oldest factors. Since the existence of supervision by BaFin (2008), there were only 8 factors founded. The youngest factor exists since 2 years (2013). The high average ratio of receivables to total assets (74.7\%) shows that factoring is the core business of factors. Subsidiaries of a financial holding are about 50 times greater than other factors in the market. Basically, for the period from 2010 to 2013, an increase in total assets and receivables are stated. This can be explained among other things by a declining number of factors in the market and a constantly increasing demand for factoring (see Table 1). An important argument for ongoing market consolidation are rising costs as a result of regulation. The sample indicates an increase in administrative expenses between 2010 and 2013. However, the increase is not significant. Furthermore, there has been a 
difference recognized between the shareholder groups but it is not significant. The increase within subsidiaries of financial holdings $(15 \%)$ is the lowest, followed by subsidiaries of non-financial holdings $(17 \%)$ and factors without any holdings (35\%).

Table 3 presents Pearson correlation coefficients for all variables considered. The results of the Pearson correlation show that there is no substantial correlation between the predictors $(r<.8)$ (Andy., Miles, \& Zoe, 2012).

Table 2. Descriptive statistics

\begin{tabular}{|c|c|c|c|c|c|}
\hline Variables & Groups & Obs. & Mean & SD & Mdn \\
\hline \multirow[t]{4}{*}{ PROF } & non- holding & 82 & .27 & .15 & .25 \\
\hline & non-financial holding & 76 & .29 & .13 & .26 \\
\hline & financial holding & 72 & .09 & .08 & .05 \\
\hline & total & 230 & .22 & .15 & .21 \\
\hline \multirow[t]{4}{*}{$M A R$} & non- holding & 85 & .74 & .18 & .78 \\
\hline & non-financial holding & 76 & .80 & .21 & .87 \\
\hline & financial holding & 70 & .67 & .22 & .75 \\
\hline & total & 231 & .74 & .21 & .81 \\
\hline \multirow[t]{4}{*}{$R O A$} & non- holding & 83 & .03 & .05 & .02 \\
\hline & non-financial holding & 76 & .05 & .04 & .05 \\
\hline & financial holding & 62 & .03 & .06 & .01 \\
\hline & total & 221 & .04 & .05 & .03 \\
\hline \multirow[t]{4}{*}{$A G E$} & non- holding & 103 & 10.83 & 8.23 & 9.00 \\
\hline & non-financial holding & 81 & 11.20 & 5.45 & 11.00 \\
\hline & financial holding & 76 & 14.82 & 9.89 & 12.00 \\
\hline & total & 260 & 12.11 & 8.20 & 11.00 \\
\hline \multirow[t]{4}{*}{ SIZE } & non- holding & 96 & 12.846 & 23.280 & 5.173 \\
\hline & non-financial holding & 78 & 11.732 & 16.159 & 7.751 \\
\hline & financial holding & 75 & 577.284 & 907.249 & 176.624 \\
\hline & total & 249 & 182.509 & 559.766 & 8.577 \\
\hline \multirow[t]{4}{*}{$R E C$} & non- holding & 96 & 10.887 & 21.885 & 2.843 \\
\hline & non-financial holding & 78 & 10.688 & 14.864 & 7.099 \\
\hline & financial holding & 75 & 548.826 & 899.756 & 149.558 \\
\hline & total & 249 & 172.854 & 550.444 & 7.581 \\
\hline \multirow[t]{4}{*}{ ADMEXP } & non- holding & 82 & .35 & .70 & .17 \\
\hline & non-financial holding & 76 & .17 & .11 & .13 \\
\hline & financial holding & 74 & .15 & .36 & .04 \\
\hline & total & 232 & .23 & .47 & .13 \\
\hline$I N T$ & total & 264 & -.21 & .54 & -.46 \\
\hline$G D P$ & total & 264 & .03 & .01 & .04 \\
\hline
\end{tabular}

Notes. PROF is measured by the ratio of interest and commissions income to receivables from customer, MAR is measured by the ratio of interest and commissions income minus interest and commissions expenses to interest and commissions income, ROA is measured by the ratio of earnings before taxes to total assets, dummy_nh, dummy_nfh and dummy_fh take the value of 1 if it is a non-holding, non-financial holding or financial holding company, otherwise 0 . AGE is measured by number of years the factors has been in existence, SIZE is measured by total assets in millions of euros, $R E C$ is measured by total receivables from customer, $A D M E X P$ is measured by the ratio of administrative expenses to receivables from the customer, GDP is measured by the ratio of this year`s GDP minus previous year`s GDP over previous year`s GDP, INT is measured by the European Central Bank. 
Table 3. Pearson correlation matrix

\begin{tabular}{|c|c|c|c|c|c|c|c|c|c|c|c|c|}
\hline No. & Variable & 1 & 2 & 3 & 4 & 5 & 6 & 7 & 8 & 9 & 10 & 11 \\
\hline 1 & PROF & 1 & $.36 * * *$ & $.42 * * *$ & $.23 * * *$ & $.32 * * *$ & $-.56^{* * * *}$ & -.02 & $-.55 * * *$ & .11 & .06 & .11 \\
\hline 2 & MAR & 219 & 1 & $.31 * * *$ & -.01 & $.21 * *$ & $-.21 * *$ & .09 & $-.30 * * *$ & -.01 & .11 & .06 \\
\hline 3 & ROA & 209 & 215 & 1 & -.13 & $.20 * *$ & -.07 & .08 & $-.15^{*}$ & .04 & .11 & .02 \\
\hline 4 & dummy_nh & 230 & 231 & 221 & 1 & $-.55^{* * * *}$ & $-.51 * * *$ & $-.13 *$ & $-.47 * * *$ & .00 & $.19 * *$ & .00 \\
\hline 5 & dummy_nfh & 230 & 231 & 221 & 264 & 1 & $-.43 * * *$ & -.08 & $-.21 * * *$ & .00 & -.09 & .00 \\
\hline 6 & dummy_fh & 230 & 231 & 221 & 264 & 264 & 1 & $.21 * * *$ & $.71 * * *$ & .00 & -.11 & .00 \\
\hline 7 & AGE & 228 & 229 & 219 & 260 & 260 & 260 & 1 & $.36 * * *$ & -.06 & -.05 & -.10 \\
\hline 8 & Ln(SIZE) & 230 & 231 & 221 & 249 & 249 & 249 & 247 & 1 & -.03 & $-.27 * * *$ & -.05 \\
\hline 9 & INT & 230 & 231 & 221 & 264 & 264 & 264 & 260 & 249 & 1 & -.04 & $.62 * * *$ \\
\hline 10 & ADMEXP & 222 & 221 & 212 & 232 & 232 & 232 & 230 & 232 & 232 & 1 & -.01 \\
\hline 11 & GDP & 230 & 231 & 221 & 264 & 264 & 264 & 260 & 249 & 264 & 232 & 1 \\
\hline
\end{tabular}

Notes. $\mathrm{N}=66 ; 1-3$ depend variables; $4-11$ predictor variables; $*$ significant at 0.05 level, $* *$ significant at 0.01 level, $* * *$ significant at 0.001 level; in the lower part of the table are reported the observations; $P R O F$ is measured by the ratio of interest and commissions income to receivables from customer, $M A R$ is measured by the ratio of interest and commissions income minus interest and commissions expenses to interest and commissions income, ROA is measured by the ratio of earnings before taxes to total assets, dummy_nh, dummy_nfh and dummy_fh take the value of 1 if it is a non-holding, non-financial holding or financial holding company, otherwise 0 . AGE is measured by number of years the factors has been in existence, SIZE is measured by natural logarithm of total assets in millions of euros, INT is measured by the European Central Bank, ADMEXP is measured by the ratio of administrative expenses to receivables from the customer, GDP is measured by the ratio of this year`s GDP minus previous year`s GDP over previous year`s GDP.

Furthermore, the results show that significant correlations between the predictors are present. Dummy_fh correlates significantly with the factor age $(A G E)$ and size $(S I Z E)$ of the factor and has a positive effect of these. Subsidiaries of a financial holding $\left(d u m m y \_f h\right)$ tend to have a higher age $(\mathrm{r}=.21)$ and a greater size $(\mathrm{r}=.71)$. Dummy_nh also correlates significantly with the factor age and size of the factor, but has a negative effect on this. Factors without any holding $\left(d u m m y \_n h\right)$ tend to have a lower age $(\mathrm{r}=-.13)$ and a smaller size $(\mathrm{r}=-.47)$. The situation is similar to subsidiaries of a non-financial holding (dummy_nfh), these tend to have a smaller size $(-.21)$.

The assumption of multicollinearity is inviolate because of the calculations of the variance inflation factor (VIF), the average VIF as well as the reciprocal VIF show no evidence of multicollinearity and confirm the results by Pearson before. The Durbin-Watson test shows that the assumption of independence is inviolate. The values are close to 2.0 and not significant. The results of the Breusch-Pagan test indicate heteroscedasticity for regression I $(P R O F)$ and regression III $(R O A)$. Therefore, the variance-covariance matrix is used, which is robust to heteroscedasticity. (Andy., Miles, \& Zoe, 2012; see Table 5).

\subsection{Methodology}

The following analysis consists of two steps. First, a comparison of means is done by the grouping variable shareholder. Following the influence of the group variable is analyzed on the profitability of the factors using different regressions.

The test results of the Shapiro-Wilk Test and the Levene's Test show that the data used is not normally distributed and there is no homogeneity of variance. To study the mean differences between the shareholder groups the non-parametric Kruskal-Wallis Test and post hoc Mann-Whitney Test are used. The results of the Kruskal-Wallis Test are reported in Table A2. The results of the Mann-Whitney Test are reported in Table 4. The effect size is calculated by:

$$
r=z / \sqrt{N}
$$

in which $\mathrm{z}$ is the $\mathrm{z}$-score and $N$ is the number of total observations on which $\mathrm{z}$ is based. Here effect sizes allow comparison between the individual effects. The interpretation of the values is based on the Cohen`s benchmark. Values smaller than .3 have a small effect, values between .3 and .5 have a medium to large effect and values above Cohen`s benchmark of .5 have a large effect. (Andy., Miles, \& Zoe, 2012).

To estimate the impact of shareholder groups on factors profitability regression analysis is used. The determinants of factors profitability are estimated in three multiple regressions. The first regression describes the influence of the predictor variables on the PROF for factors $i=1, \ldots, N$ and is given by:

$$
P R O F_{i}=\beta_{0}+\beta_{1} d u m m y_{-} n f h_{i}+\beta_{2} d u m m y_{-} f h_{i}+\beta_{3} A G E_{i}+\beta_{4} \operatorname{Ln}(S I Z E)_{i}+\beta_{5} G D P_{i}+\varepsilon_{i}
$$


The second regression describes the influence of the predictor variables on the MAR and is given by:

$$
M A R_{i}=\beta_{0}+\beta_{1} d u m m y_{-} n f h_{i}+\beta_{2} d u m m y_{-} f h_{i}+\beta_{3} A G E_{i}+\beta_{4} \operatorname{Ln}(S I Z E)_{i}+\beta_{5} I N T_{i}+\beta_{6} G D P_{i}+\varepsilon_{i}
$$

The third regression describes the influence of the predictor variables on the ROA and is given by:

$$
R O A_{i}=\beta_{0}+\beta_{1} d u m m y_{-} n f h_{i}+\beta_{2} d_{u m m y \_} f h_{i}+\beta_{3} A G E_{i}+\beta_{4} \operatorname{Ln}(S I Z E)_{i}+\beta_{5} A D M E X P_{i}+\beta_{6} G D P_{i}+\varepsilon_{i}
$$

To verify the autocorrelation the Durbin-Watson test is used. With the Breusch-Pagan test, the homoscedasticity is tested.

\section{Results}

\subsection{Kruskal-Wallis and Mann-Whitney Tests}

The results from Kruskal-Wallis Test show highly significant differences between the shareholder groups. The results from the Kruskal-Wallis Test are shown in Table A2. The non-parametric post hoc Mann-Whitney Tests was used to follow-up this findings. In the following results, the median is reported since it is more appropriate for non-parametric tests (Andy., Miles, \& Zoe, 2012). Table 4 shows the results from the Mann-Whitney test. For medians or means see Table 2.

To conclude the results from the Kruskal-Wallis Tests and the Mann-Whitney Tests, the main effect sizes (r) are summarized. Measured by PROF factors with financial holdings $(\mathrm{Mdn}=.09)$ are significantly less profitable than factors with non-holding ( $\mathrm{Mdn}=.29)$ or non-financial holding $(\mathrm{Mdn}=.27)(\mathrm{r}>.5)$. The situation is similar at the margin $(M A R)$, factors with financial holdings $(\mathrm{Mdn}=.67)$ show the smallest margin, followed by factors with non-holdings $(\mathrm{Mdn}=.74)$. However, the size effects are only medium $(0.5>\mathrm{r}>0.3)$. Factors with non-financial holdings $(\mathrm{Mdn}=.05)$ also have the highest $R O A$, followed by factors without any holding (Mdn $=.03)$. The size effects are also only medium $(0.5>r>0.3)$. At $A G E$ only significant differences between factors without any holding $(\mathrm{Mdn}=10.83)$ and factors with financial holdings $(\mathrm{Mdn}=14.82)$ should be reported. The latter are on average older. However, all size effects are small $(\mathrm{r}<.3)$. Regarding the SIZE, all groups differ significantly from each other. Factors with financial holding $(\mathrm{Mdn}=577.28)$ are significantly larger than any other, with large size effects $(\mathrm{r}>.5)$. The SIZE difference between factors without any holding $(\mathrm{Mdn}=12.84)$ and factors with non-financial holding ( $\mathrm{Mdn}=11.73)$ is also significant, but only with a small size effect $(\mathrm{r}<.3)$. Interesting and not surprising is the cost structure of the factors. Factors with financial holdings $(\mathrm{Mdn}=.15)$ have by far the lowest administrative expenses $(A D M E X P)$. The size effect is large $(r>.5)$. The highest administrative expenses count factors without any holding $(\mathrm{Mdn}=.35)$.

\begin{tabular}{|c|c|c|c|c|c|c|}
\hline & \multicolumn{2}{|c|}{ non-holding } & \multicolumn{2}{|c|}{ non-financial holding } & \multicolumn{2}{|c|}{ financial holding } \\
\hline & non-financial holding & financial holding & non-holding & financial holding & non-holding & non-financial holding \\
\hline \multirow{2}{*}{ PROF } & 2856.5 & $924.0 * * *$ & 2856.5 & $414.0^{* * * *}$ & $924.0^{* * *}$ & $414.0 * * *$ \\
\hline & $-.9(-.07)$ & $-7.3(-.6)$ & $-.9(-0.07)$ & $-8.9(-.7)$ & $-7.3(-.6)$ & $-8.9(-.7)$ \\
\hline \multirow{2}{*}{$M A R$} & $2042.0 * * *$ & $2436.0^{*}$ & $2042.0^{* * *}$ & $1277.0^{* * *}$ & $2436.0^{*}$ & $1277.0 * * *$ \\
\hline & $-4.0(-.3)$ & $-1.9(-.2)$ & $-4.0(-.3)$ & $-5.4(-.4)$ & $-1.9(-.2)$ & $-5.4(-.4)$ \\
\hline \multirow{2}{*}{$R O A$} & $2017.0 * * *$ & 2107.5 & $2017.0 * * *$ & $1167.0 * * *$ & 2107.5 & $1167.0 * * *$ \\
\hline & $-3.9(-.3)$ & $-1.9(-.2)$ & $-3.9(-0.3)$ & $-5.1(-.4)$ & $-1.9(-.2)$ & $-5.1(-.4)$ \\
\hline \multirow{2}{*}{$A G E$} & 3584.0 & $2873.0 * *$ & 3584.0 & 2585.0 & $2873.0^{* *}$ & 2585.0 \\
\hline & $-1.6(-.1)$ & $-3.0(-.2)$ & $-1.6(-.1)$ & $-1.7(-.1)$ & $-3.0(-0.2)$ & $-1.7(-.1)$ \\
\hline \multirow{2}{*}{ SIZE } & $2710.0^{* *}$ & 595.0 & $2710.0^{* *}$ & $373.0^{* * * *}$ & $595.0^{* * * *}$ & $373.0^{* * * *}$ \\
\hline & $-3.1(-.2)$ & $-9.4(-.7)$ & $-3.1(-.2)$ & $-9.3(-.8)$ & $-9.4(-.7)$ & $-9.3(-.8)$ \\
\hline \multirow{2}{*}{ ADMEXP } & $2447.0 * *$ & $1091.0 * * *$ & $2447.0 * *$ & $1127.5^{* * *}$ & $1091.0 * * *$ & $1127.5^{* * *}$ \\
\hline & $-2.3(-.2)$ & $-6.9(-.6)$ & $-2.3(-.2)$ & $-6.3(-.5)$ & $-6.9(-.6)$ & $-6.3(-.5)$ \\
\hline
\end{tabular}

Table 4. Results from Mann-Whitney test

Notes. value of Mann-Whitney`s U statistic (U) and p-value with * significant at 0.05 level, ** significant at 0.01 level, *** significant at 0.001 level; associated z approximation (z); effect sizes (r) in parentheses; PROF is measured by the ratio of interest and commissions income to receivables from customer, MAR is measured by the ratio of interest and commissions income minus interest and commissions expenses to interest and commissions income, $R O A$ is measured by the ratio of earnings before taxes to total assets, $A G E$ is measured by number of years the factors has been in existence, SIZE is measured by total assets, ADMEXP is measured by the ratio of administrative expenses to receivables from the customer. 


\subsection{Regressions}

Table 5 gives a brief overview of the regression results.

Table 5. Regression analysis

\begin{tabular}{lccc}
\hline & PROF $(\mathrm{I})$ & MAR (II) & ROA (III) \\
\hline dummy_nfh & $.03(1.66)$ & $.09(2.80)^{* * *}$ & $.03(4.11)^{* * *}$ \\
dummy_fh & $-.10(-3.68)^{* * *}$ & $.07(1.54)$ & $.02(1.48)$ \\
Ln(SIZE) & $-.03(-4.55)^{* * *}$ & $-.04(-4.86)^{* * *}$ & $-.01(-1.86)$ \\
$A G E$ & $.01(3.77)^{* * *}$ & $.01(3.68)^{* * *}$ & $.00(1.72)$ \\
INT & & $-.02(-.76)$ & $.01(2.35)^{*}$ \\
$A D M E X P$ & & & $.01(.32)$ \\
GDP & $1.59(2.56)^{*}$ & $1.98(1.51)$ & $.10(1.83)$ \\
Intercept & $.57(6.11)^{* * *}$ & $1.27(8.65)^{* * *}$ & .13 \\
$\mathrm{R}^{2}$ & .41 & .18 & .10 \\
$\mathrm{R}^{2}$ (adj) & .39 & .15 & $\mathrm{~F}_{(6,206)}=4.95 * * *$ \\
F-statistic & $\mathrm{F}_{(5,222)}=30.49^{* * *}$ & $\mathrm{~F}_{(6,222)}=7.90 * * *$ & 1.92 \\
Durbin-Watson & 2.06 & 2.23 & $\chi=17.38^{* *}$ \\
Breusch-Pagan & $\chi=19.38^{* * *}$ & $\chi=9.35$ & \\
\hline
\end{tabular}

Notes. observations from 2010 to 2013; betas are reported; t-values are in parentheses; Durbin-Watson test, D-W statistics are reported;

* significant at 0.05 level, ** significant at 0.01 level, *** significant at 0.001 level; PROF is measured by the ratio of interest and commissions income to receivables from customer, MAR is measured by the ratio of interest and commissions income minus interest and commissions expenses to interest and commissions income, ROA is measured by the ratio of earnings before taxes to total assets, dummy_nh, dummy_nfh and dummy_fh take the value of 1 if it is a non-holding, non-financial holding or financial holding company, otherwise 0 . SIZE is measured by natural logarithm of total assets, $A G E$ is measured by number of years the factors have been in existence, INT is measured by the European Central Bank, ADMEXP is measured by the ratio of administrative expenses to receivables from the customer, GDP is measured by the ratio of this year`s GDP minus previous year`s GDP over previous year`s GDP.

The predictor variables used in the regressions could explain $41 \%$ of the variance of the $P R O F, 18 \%$ of the variance of the MAR and $13 \%$ of the variance of ROA. In all regressions the shareholder dummies were the strongest predictor. This has the characteristics dummy_nfh and dummy_fh. GDP is only to describe the PROF a significant predictor.

The profitability $(P R O F)$ is negatively affected by dummy_fh $(\beta=-.10)$. This means that a subsidiary of a financial group tend to have lower profitability. Here, the strong correlation between dummy $f h$ and SIZE becomes clear. The size has a small negative effect on the profitability $(\beta=-.03)$. An increase in the size tends to lower profitability. The effect of age is also significant, but leads to a very low positive effect on the profitability $(\beta=.01)$. The situation of the overall economy has the greatest positive effect on the profitability $(\beta=1.39)$. In good economic times, the companies tend to be more profitable.

These significant effects cannot be stated in the regressions II and III. Subsidiaries of a non-financial holding (dummy_nfh) have a significant positive effect $(\beta=.09)$ on the margin $(M A R)$. The size also has a significant effect on the margin $(\beta=-.04)$. An increasing size tends to have a negative impact on the margin. At interest rates no significant effect on the margin is determined.

The regression III shows that subsidiaries of a non-financial holding have a highly significant but only a small positive effect on the ROA ( $\beta=.03)$. The small significant positive effect of increasing administrative expenses to the ROA $(\beta=.01)$ is not immediately comprehensible. The administrative expenses are in relation to the average volume of receivables, so that this variable only increases when the administrative expenses rise or the average volume of receivables decreases. A lower volume of receivables would lead to low interest and commission income, so that this effect could be explained only by increasing administrative expenses combined with increasing interest and commission income. However, there is no significant correlation between PROF and $A D M E X P$. Only the SIZE has a significant negative effect on administrative expenses.

Due to the low explained variance of $M A R$ and $R O A$ and the unexplained effect of administrative expenses to the $R O A$ only the $P R O F$ is taken into consideration in the discussion.

\section{Discussion}

The empirical results have shown that the hypothesis of the shareholder is closely linked to the hypothesis of the 
size effect. Thus no distinction is made in the following discussion between the hypotheses.

The factors' profitability is dependent on the shareholders group. Factors of a financial holding tend to be less profitable than others. The profitability is calculated by the difference between interest and commission income and interest and commission expenses in relation to the volume of receivables from the customer. Thus, a lower level of profitability can be explained by lower income at constant expenses or increased expenses at constant income. Assuming that factors of financial holdings primarily have major clients in the portfolio and this could be won only through lower conditions or the in-house factoring leads to lower income, lower incomes are possible. Inhouse-factoring is particularly preferred by large clients (Smith \& Schnucker, 1993; Hartmann-Wendels \& Stöter, 2012).

A general variation of the interest and commission expenses from subsidiaries is conceivable because the income from the factoring business can be attributed to the income statement at an early stage by higher interest expenses or high commission expenses to the financial or non-financial holding. In particular, if the factor uses the equity base of the holding to refinance. It is striking that there are significantly distinguish between subsidiaries of non-financial and financial holding. Thus, this conclusion would be true only for factors of financial holdings. It would be different under the assumption that portfolios of subsidiaries of non-financial holdings are primarily dominated by SMEs. This would lead to higher income, because SMEs rather ask the product full-service factoring or the retail business does not count to the core business of factors of a non-financial holding.

It is hypothesized that the size of factors has a negative effect on the profitability. This is based on the assumption that an increase in size of the factor improve the quality of industrial and credit information. A higher quality of information enables large factors a better business outlook and adjusting the factoring conditions to attract customers. At the same time it is assumed that the shareholder groups influence the profitability, because the shareholder groups correlate significantly with the size of the factor. The results show that large factors or factors of a financial holding have a lower profitability than small factors or factors of a non-financial holding or without any holding, in Germany. Considering the assumption made, this means that better credit information lead to lower profitability. This result complements the existing research on factoring. According to Klapper (2006) and Borgia et al. (2010), a decreasing information asymmetry or good credit information have a generally positive impact on the provision of factoring (factoring turnover). Summers and Wilson (2000) argue similarly, thus factoring is more likely when a close day to day relationship between the factor and the firm exists. Hence, good credit information lead to a higher factoring turnover, especially for small customers. At the same time, this information may have negative impact on the profitability of large factors, because the price mechanism might be used for customer acquisition.

Factors of a financial holding tend, compared to other market players, to lower margins. The margin is the difference between direct income and direct expenses in relation to the direct income. Thus, an increase in income or decrease in expenses results in rising margins. For the data set, this means that institutions of a financial holding have lower income or higher expenses. Both options can be considered (see arguments of profitability).

Factors without any holding and factors of a non-financial holding show significantly higher margins. It is likely that the incomes are higher, particularly for factors without any holding. They often use credit loans from banks to refinance. Higher incomes are signs against a retail business, so that factors are able to impose higher conditions without holding affiliation or factors of a non-financial holding. However, the calculated margin does not include any administrative expenses. Administrative expenses of factors of a financial holding tend to be significantly lower, so that lower margins can be justified by lower consequential costs within the institute. Thus, transactions are possible with lower margins.

Against the background of continuing market consolidation, the comparison of realized margins, incurred administrative expenses and profitability is crucial. Factors without any holding are significantly smaller than other market players, show significantly higher administrative expenses and achieve only marginally higher margins than others. But they are profitable in relation to average volume of receivables from customers.

The size of the factors is highly correlated with the shareholder group. Large factors have better opportunities at retail business as well as business with large clients. However, SMEs also have special financing requirements, in particular individual purchase frames so that smaller institutions still have their place, so long as they remain profitable and have proportionate administrative expenses. Therefore, a further market consolidation can be expected. But small and profitable factors will continue to survive in the market. However, administrative expenses should be reduced by small factors. The factors show no significant differences in the ROA, at the 
same time the ROA is very low. The positive effect of administrative expenses to the ROA cannot be explained.

These results show that the assumptions of the hypothesis are accurate. Profitability and margins are negatively affected by the size of the factor as well as the shareholders group. In addition to the size effect no age effect was found.

\section{Conclusion}

The German factoring industry is dominated by banks. The results show that the largest players are bank-owned. So German factors are an extension of the banking industry. SMEs justify the use of factoring often with a desire for independence of the (house-) bank. This motivation can only be confirmed if SMEs are primarily clients of small and non-bank factors. The results suggest this conclusion. Compared to foreign markets, the German factoring market is characterized by growth rates above average showing future growth potential in an ongoing market consolidation. Further market consolidation is probable because the administrative expenses of small factors and factors without any holding are high. Another driver of consolidation is the increase in equity requirements as a result of restrictive regulatory regime. However, subsidiaries of a financial holding or non-financial holding show significantly lower administrative expenses. The results show that the profitability of the factors is significantly influenced by the shareholders and the size of the factor. Factors of a financial holding are significantly less profitable than factors without any holding or factors of a non-financial holding. A similar picture emerges in the achieved margins of factors. Future analyzes of the German factoring industry should include an analysis of the business models and clients portfolios of German factors, so that the present results can be further underpinned.

\section{References}

BaFin. (2011). Federal Financial Supervisory Authority. Annual Report 2010. Retrieved from http://www.bafin.de/SharedDocs/Downloads/EN/Jahresbericht/dl_annualreport_2010.html?nn=2821414

BaFin. (2014). Federal Financial Supervisory Authority. Annual Report 2013. Retrieved from http://www.bafin.de/SharedDocs/Downloads/EN/Jahresbericht/dl_annualreport_2013.html?nn=2821414

BaFin. (2015). Federal Financial Supervisory Authority. Corporate Database. Retrieved from http://www.bafin.de/SharedDocs/Downloads/DE/Liste/Unternehmensdatenbank/dl_li_fidi_leas_fac.html

Bank for the Accounts of Companies Harmonized. (2015). European database containing aggregate information on non-financial companies. Retrieved from https://www.bach.banque-france.fr/

Borgia, D. J., Swaleheen, M., Jones, T. L., \& Weeks, H. S. (2010). Accounts Receivable Factoring As A Response To Weak Governance: Panel Data Evidence. International Business \& Economics Research Journal, 9(2), 11-22. Retrieved from http://www.cluteinstitute.com/ojs/index.php/IBER/article/view/517/504

Coase, R. H. (1937). The Nature of the Firm. Economica, New Series, 16, 386-405. http://dx.doi.org/10.1111/j.1468-0335.1937.tb00002.x

Company Register. (2015). Annual Balance Sheets, Bundesanzeiger Verlag. Retrieved from https://www.unternehmensregister.de/ureg/index.html;jsessionid=CBEA910BAEE3915ECFCA325412DD2 EA,number of accounts receivables"F.web04-1

Deloof, M. (2003). Does Working Capital Management Affect Profitability of Belgian Firms? Journal of Business Finance \& Accounting, 30(3\&4), 573-587. http://dx.doi.org/10.1111/1468-5957.00008

Deutsche Bundesbank. (2012). The importance of trade credit for corporate financing in Germany - evidence from financial statements statistics. Monthly Report, October 2012, 51-63. Retrieved from https://www.bundesbank.de/Redaktion/EN/Downloads/Publications/Monthly_Report/2012/2012_10_month ly_report.pdf?_blob=publicationFile

Diamond, D. W. (1984). Financial Intermediation and Delegated Monitoring. The Revies of Economic Studies, 51(3), 393-414. http://dx.doi.org/10.2307/2297430

European Central Bank. Statistical Data Warehouse. Retrieved from http://sdw.ecb.europa.eu/

Factor Chain International. Statistics. Retrieved from http://www.fci.nl/about-fci/statistics

Field, A., Miles, J., \& Field, Z. (2012). Discovering Statistics Using R. (1st ed.). Sage Publications.

German Factoring Association. (2011). Wachsen mit Factoring, Nutzen und Erfahrungen in Deutschland. Retrieved from http://www.factoring.de/studie-der-universität-zu-köln 
German Factoring Association. (2015). Апnиаl Report 2014. Retrieved from http://www.factoring.de/jahresbericht-2014

Hartmann-Wendels, T., \& Stöter, A. (2012). Accounts Receivable Management and the Factoring Option: Evidence from a Bank-Based Economy. Social Science Research Network, 1-22. http://dx.doi.org/10.2139/ssrn.2140870

Hawkins, D. (1993). The business of factoring: A guide to factoring and invoice discounting. McGraw-Hill.

Hoppenstedt Firmendatenbank. (2015). Hoppenstedt Firmendatenbank [Hoppenstedt corporate database]. Darmstadt: Hoppenstedt Firmeninformationen.

Klapper, L. (2006). The Role of Factoring for Financing Small and Medium Enterprises. Journal of Banking \& Finance, 30(11), 3111-3130. http://dx.doi.org/10.1016/j.jbankfin.2006.05.001

Lea, T., \& Trollope, W. (1996). A guide to factoring and invoice discounting: The new bankers. Chapman \& Hall.

Martínez-Sola, C., García-Teruel, P., \& Martínez-Solano, P. (2014). Trade credit and SME profitability. Small Business Economics, 42, 561-577. http://dx.doi.org/10.1007/s11187-013-9491-y

Mian, S. L., \& Smith Jr., C. W. (1992). Accounts Receivable Management Policy: Theory and Evidence. The Journal of Finance, 47(1), 169-200. http://dx.doi.org/10.1111/j.1540-6261.1992.tb03982.x

Sakyi, P. A., Ofoeda, I., Kyereboah-Coleman, A., \& Abor, J. Y. (2014). Risk and Performance of Non-Bank Financial Institutions, International Journal Financial Services Management, 7(1), 19-35. http://dx.doi.org/10.1504/ijfsm.2014.062289

Smith, J. K., \& Schnucker, C. (1993). An empirical examination of organizational structure: The economics of the factoring decision. Journal of Corporate Finance, Part 1, 119-138. http://dx.doi.org/10.1016/0929-1199(94)90012-4

Summers, B., \& Wilson, N. (2000). Trade Credit Management and the Decision to Use Factoring: An Empirical Study. Journal of Business Finance \& Accounting, 27(1), 37-68. http://dx.doi.org/10.1111/1468-5957.00305

Summers, B., \& Wilson, N. (2003). Trade Credit and Customer Relationships, Managerial and Decision Economics, 24, 439-455. http://dx.doi.org/10.1002/mde.1041

\section{Note}

Note 1. The AG and GmbH are German corporations, whereas the GmbH \& Co. KG is a German partnership. The AG can be compared with a public limited company (PLC), the GmbH with a private limited company by shares (Ltd.) and the $\mathrm{GmbH} \& \mathrm{Co}$. KG with a limited liability partnership (LLP).

\section{Appendix A}

Table A1. Mean of the variables (2010-2013)

\begin{tabular}{llcccc}
\hline Variables & Groups & 2010 & 2011 & 2012 & 2013 \\
\hline PROF & non- holding & $.29(22)$ & $.31(21)$ & $.25(23)$ & $.24(16)$ \\
& non-financial holding & $.31(19)$ & $.29(21)$ & $.28(21)$ & $.29(15)$ \\
& financial holding & $.10(18)$ & $.11(18)$ & $.09(18)$ & $.08(18)$ \\
& total & $.23(59)$ & $.24(60)$ & $.21(62)$ & $.19(49)$ \\
& non- holding & $.75(22)$ & $.79(21)$ & $.75(25)$ & $.79(17)$ \\
& non-financial holding & $.82(19)$ & $.74(21)$ & $.80(21)$ & $.81(15)$ \\
& financial holding & $.73(17)$ & $.65(18)$ & $.67(18)$ & $.71(17)$ \\
& total & $.76(58)$ & $.73(60)$ & $.72(64)$ & $.75(49)$ \\
& non- holding & $.04(21)$ & $.04(19)$ & $.04(24)$ & $.03(19)$ \\
& non-financial holding & $.03(19)$ & $.05(21)$ & $.06(21)$ & $.05(15)$ \\
& financial holding & $.01(15)$ & $.01(15)$ & $.02(16)$ & $.02(16)$ \\
& total & $.04(55)$ & $.04(55)$ & $.04(61)$ & $.03(50)$ \\
& non- holding & $9.60(25)$ & $10.60(26)$ & $11.60(26)$ & $12.60(26)$ \\
& non-financial holding & $10.32(19)$ & $11.32(20)$ & $12.32(21)$ & $13.32(21)$ \\
& financial holding & $13.32(19)$ & $14.32(19)$ & $15.32(19)$ & $16.32(19)$ \\
& total & $10.94(63)$ & $11.60(65)$ & $12.42(66)$ & $13.42(66)$ \\
\hline
\end{tabular}




\begin{tabular}{llcccc}
\hline SIZE & non- holding & $10.857(25)$ & $15.999(26)$ & $17.477(26)$ & $15.623(19)$ \\
& non-financial holding & $11.140(20)$ & $12.169(21)$ & $14.560(21)$ & $16.693(16)$ \\
& financial holding & $612.576(19)$ & $642.767(19)$ & $553.097(19)$ & $594.422(18)$ \\
& total & $179.376(64)$ & $183.963(66)$ & $160.415(66)$ & $211.993(53)$ \\
$R E C$ & non- holding & $8.948(25)$ & $14.127(26)$ & $14.791(26)$ & $13.319(19)$ \\
& non-financial holding & $10.003(20)$ & $11.276(21)$ & $13.367(21)$ & $15.040(16)$ \\
& financial holding & $595.232(19)$ & $622.469(19)$ & $516.234(19)$ & $552.692(18)$ \\
& total & $173.212(64)$ & $177.313(66)$ & $149.013(66)$ & $196.559(53)$ \\
\multirow{2}{*}{ ADMEXP } & non- holding & $.19(22)$ & $.20(20)$ & $.17(23)$ & $.21(17)$ \\
& non-financial holding & $.20(19)$ & $.16(21)$ & $.14(21)$ & $.17(15)$ \\
& financial holding & $.10(18)$ & $.11(19)$ & $.13(19)$ & $.12(18)$ \\
& total & $.25(59)$ & $.19(60)$ & $.22(63)$ & $.25(50)$ \\
INT & total & $.33(66)$ & $.71(66)$ & $-.59(66)$ & $-.62(66)$ \\
\hline$D P P$ & total & $.05(66)$ & $.05(66)$ & $.02(66)$ & $.03(66)$ \\
\hline
\end{tabular}

Notes. PROF is measured by the ratio of interest and commissions income to receivables from customer, MAR is measured by the ratio of interest and commissions income minus interest and commissions expenses to interest and commissions income, ROA is measured by the ratio of earnings before taxes to total assets, dummy_nh, dummy_nfh and dummy_fh take the value of 1 if it is a non-holding, non-financial holding or financial holding company, otherwise $0 . A G E$ is measured by number of years the factors has been in existence, SIZE is measured by total assets in millions of euros, $R E C$ is measured by total receivables from customer, $A D M E X P$ is measured by the ratio of administrative expenses to receivables from the customer, $G D P$ is measured by the ratio of this year`s GDP minus previous year`s GDP over previous year`s GDP, INT is measured by the European Central Bank.

Table A2. Results from Kruskal-Wallis tests

\begin{tabular}{lccc}
\hline Variables & $\mathrm{H}$ & $\mathrm{df}$ & $\mathrm{p}$ \\
\hline PROF & 87.779 & 2 & $<.000^{* * *}$ \\
MAR & 32.401 & 2 & $<.000^{* * *}$ \\
ROA & 29.540 & 2 & $<.000^{* * *}$ \\
$A G E$ & 10.072 & 2 & $<.000^{* * *}$ \\
SIZE & 117.824 & 2 & $<.000^{* * *}$ \\
ADMEXP & 60.957 & 2 & $<.000^{* * *}$ \\
\hline
\end{tabular}

Notes. grouping variable is shareholder (non-holding, non-financial holding, financial holding); $\mathrm{H}$ is the test statistic for the Kruskal-Wallis test; $\mathrm{df}$ is associated degrees of freedom; $\mathrm{p}$-value, * significant at 0.05 level, ** significant at 0.01 level, *** significant at 0.001 level; PROF is measured by the ratio of interest and commissions income to receivables from customer, MAR is measured by the ratio of interest and commissions income minus interest and commissions expenses to interest and commissions income, ROA is measured by the ratio of earnings before taxes to total assets, $A G E$ is measured by number of years the factors has been in existence, SIZE is measured by total assets in millions of euros, $A D M E X P$ is measured by the ratio of administrative expenses to receivables from the customer.

\section{Copyrights}

Copyright for this article is retained by the author(s), with first publication rights granted to the journal.

This is an open-access article distributed under the terms and conditions of the Creative Commons Attribution license (http://creativecommons.org/licenses/by/3.0/). 